\title{
TINGKAT KEMAMPUAN FOREHAND GROUNDSTROKE DAN BACKHAND GROUNDSTROKE SISWA SEKOLAH TENIS MENOREH TENNIS CLUB, HANDAYANI TENNIS CLUB DAN BANTUL TENNIS CAMP
}

\author{
Ngatman dan Erman Sulistyatna \\ Pendidikan Jasmani dan Rekreasi FIK UNY, Yogyakarta
}

\begin{abstract}
Forehand groundstroke and backhand groundstroke are some of the most important techniques in tennis. Most players lose their points because they do not master forehand groundstroke and backhand groundstroke properly. This study aimed to determine the level of forehand groundstroke and backhand groundstroke of the students of Menoreh Tennis Club, Handayani Tennis Club and Bantul Tennis Camp.

This study employed survey method using data gathering techniques with test and measurements. The instrument used in this study was Dyer Tennis Test. Dyer Tennis Test validity is 0.80 to 0.90 and the reliability of this instrument is 0.90 . The subjects of the study were all students of Menoreh Tennis Club, Handayani Tennis Club and Bantul Tennis Camp. There were 32 students, 20 male and 12 female.

The result of this study showed that the level of forehand groundstrokes of the students of Menoreh Tennis Club, Handayani Tennis Club and Bantul Tennis Camp were categorized as "moderate". In detail there were 2 students (6.25\%) categorized as "Excellent", 5 students $(15.63 \%)$ were categorized as "Good", 15 students (46.87\%) were categorized as "Moderate", 8 students $(25 \%)$ were categorized as "poor" and 2 students $(6.25 \%)$ were categorized as low. The average of backhand ground strokes skills was categorized as "moderate", which in details were 2 students $(6.25 \%)$ categorized as "Excellent", 8 students $(25 \%)$ were categorized as "good", 12 students $(37.5 \%)$ were categorized as "moderate", 8 students $(25 \%)$ were categorized as "poor" and 2 students $(6.25 \%)$ were categorized as "low". The average of forehand groundstroke and backhand groundstroke were categorized as "moderate", in details there were 2 students $(6.25 \%)$ categorized as "Excellent", 5 students (15.63\%) were categorized as "Good", 15 students $(46.87 \%)$ were categorized as "Moderate", 8 students $(25 \%)$ were categorized as "poor" and 2 students $(6.25 \%)$ were categorized as low.

The study showed that the level of forehand groundstroke and backhand groundstroke of the students of Menoreh Tennis Club, Handayani Tennis Club and Bantul Tennis Camp were modereate.
\end{abstract}

Keywords: forehand ground strokes, backhand ground strokes, Tennis academy students, dyer tennis test

\section{ABSTRAK}

Teknik forehand groundstroke dan backhand groundstroke merupakan salah satu teknik yang sangat penting dalam permainan tenis lapangan. Petenis kebanyakan kehilangan angka karena tidak menguasai teknik forehand groundstroke dan backhand groundstroke dengan baik. Penelitian ini bertujuan untuk mengetahui tingkat kemampuan forehand groundstroke dan backhand groundstroke padasiswa sekolah tenis Menoreh Tennis Club, Handayani Tennis Club dan Bantul Tennis Camp.

Penelitian ini menggunakan metode survei dengan teknik pengumpulan data menggunakan tes dan pengukuran. Instrumen yang digunakan dalam penelitian ini adalah Dyer Tennis Test. Validitas instrumen Dyer Tennis Test antara 0,80 sampai 0,90 dan reliabilitas instrumen adalah 0,90. Subjek dalam penelitian ini adalah seluruh siswa sekolah tenis Menoreh Tennis Club, 
Handayani Tennis Club dan Bantul Tennis Camp sebanyak 32 siswa, terdiri dari 20 siswa laki-laki dan 12 siswa perempuan.

Hasil penelitian menunjukkan bahwa tingkat kemampuan forehand groundstrokes siswa sekolah tenis Menoreh Tennis Club, Handayani Tennis Club dan Bantul Tennis Camp berkategori "sedang". Secara terperinci terdapat 2 siswa (6,25\%) berkategori "baik sekali", 5 siswa $(15,63 \%)$ berkategori "baik", 15 siswa (46,87\%) berkategori "sedang", 8 siswa (25\%) berkategori "kurang" dan 2 siswa (6,25\%) rendah. Rata-rata tingkat kemampuan backhand groundstrokes berkategori "sedang", dengan rincian terdapat 2 siswa $(6,25 \%)$ berkategori "baik sekali", 8 siswa (25\%) berkategori "baik", 12 siswa (37,5\%) berkategori "sedang", 8 siswa (25\%) berkategori "kurang" dan 2 siswa (6,25\%) berkategori "rendah". Rata-rata tingkat kemampuan forehand groundstroke dan backhand groundstroke berkategori "sedang", dengan rincian terdapat 2 siswa $(6,25 \%)$ berkategori "baik sekali", 5 siswa (15,63\%) berkategori "baik", 15 siswa (46,87\%) berkategori "sedang", 8 siswa (25\%) berkategori "kurang" dan 2 siswa $(6,25 \%)$ rendah.

Penelitian ini menunjukkan bahwa tingkat kemampuan forehand groundstroke dan backhand groundstroke siswa sekolah tenis Menoreh Tennis Club, Handayani Tennis Club dan Bantul Tennis Camp berkategori sedang.

Kata kunci: forehand groundstrokes, backhand groundstrokes, siswa sekolah tenis, dyer tennis test

\section{PENDAHULUAN}

Tenis lapangan merupakan salah satu jenis olahraga yang sangat dikenal oleh masyarakat saat ini. Sekarang ini tenis sudah mendapat perhatian yang cukup besar dari masyarakat. Hal ini dapat dilihat dari tingginya animo dan banyaknya minat masyarakat yang bermain tenis lapangan mulai dari anak-anak sampai orang dewasa. Olahraga tenis lapangan bukan lagi hanya sekedar ingin mencari kebugaran atau untuk rekreasi, tapi juga sudah dijadikan sebagai sarana untuk mencapai prestasi.

Program pengembangan olahraga tenis akan berhasil dengan baik apabila ada dukungan dari berbagai pihak, diantaranya: dukungan dari pemerintah, dinas pendidikan, dan masyarakat. Salah satu program pengembangan dan permasalahan olahraga tenis di kalangan anak usia muda dapat ditempuh melalui perkumpulan/klub/sekolah tenis sebagai wahana untuk membina olahraga tenis di kalangan usia muda. Dengan semakin banyak berdiri sekolah tenis maupun kejuaraan-kejuaraan tenis maka akan mendorong berdirinya sentra-sentra latihan untuk pembinaan tenis usia dini baik dalam bentuk individu (privat) maupun sekolah tenis.

Berbagai sekolah tenis/klub di DIY yang membina petenis usia dini, di antaranya: sekolah tenis Mercu Buana, Damas Tennis School,Sichata, Hadayani Tennis Club, Bantul Tennis Camp, Menoreh Tennis Club dan Selabora FIK UNY. Dengan berdirinya sekolah/klub tenis tersebut diharapkan dapat dipergunakan sebagai wadah untuk membina dan mengasah kemampuan petenis usia muda.

Berdasarkan hasil observasi peneliti dari siswa-siswa sekolah tenis tersebut pada saat latihan dan bertanding masih banyak mengalami kekalahan/kegagalam karena tidak 
memiliki tingkat konsistensi/keajegan dalam melakukan forehand groundstroke dan backhand groundstroke. Jindrich \& Klavora (1987: 19) mengatakan bahwa teknik groundstrokes merupakan teknik yang sangat dominan digunakan selama dalam permainan tenis. Lebih lanjut dikatakan bahwa $47 \%$ teknik pukulan yang dilakukan selama dalam permainan tenis adalah teknik groundstrokes. Artinya, karena banyaknya pukulan groundstrokes yang dilakukan dalam pertandingan/latihan, maka sangat perlu bagi pemain untuk menguasai dan memiliki konsistensi pukulan groundstrokes (forehand dan backhand).

Melalui penelitian ini diharapkan dapat diketahui bagaimana tingkat kemampuan forehand groundstroke dan backhand groundstroke. Di samping itu, disekolah tenis Menoreh Tennis Club, Handayani Tennis Club dan Bantul Tennis Camp belum pernah diadakan penelitian untuk mengetahui tingkat kemampuan forehand groundstrokes dan backhand groundstrokes.

\section{KAJIAN PUSTAKA Forehand Groundstroke}

Pukulan forehand merupakan pukulan yang dilakukan dengan tangan kanan dari sebelah kanan badan, terkecuali bila pemain itu kidal (Abdoellah, 1981:513). Forehand groundstrokes adalah teknik pukulan dasar dalam permainan bola tenis yang dilakukan setelah bola memantul di lapangan dan dilakukan pada sisi forehand.
Gerakan forehand groundstrokes dapat dibagi menjadi tiga tahap yaitu: tahap ayunan ke belakang (backswing), tahap saat perkenaan bola dengan raket (point of contact), serta tahap saat gerak lanjutan (follow through). Dalam pelaksanaannya ketiga tahap ini harus merupakan satu kesatuan gerak dan harus dilakukan secara simultan.

forehand groundstroke adalah teknik pukulan dasar dalam permainan bola tenis yang dilakukan setelah bola memantul di lapangan dan dilakukan dengan tangan kanan dari sebelah kanan badan, terkecuali bila pemain itu kidal dengan tahapan backswing, point of contact, dan followthrough (Brown, 2007:31-32).

\section{Backhand Groundstrokes}

Pukulan backhand merupakan pukulan yang dilakukan dengan tangan kanan tetapi dari sebelah kiri badan bagi petenis yang tidak memegang raket dengan menggunakan tangan kiri (Arma Abdoellah, 1981: 514). Backhand groundstroke adalah teknik pukulan dasar dalam permainan tenis yang dilakukan setelah bola memantul di lapangan dan dilakukan dari sisi backhand. Gerakan backhand groundstroke pada prinsipnya hampir sama dengan forehand groundstroke yang terdiri dari tiga tahap, yaitu tahap ayunan kebelakang (backswing), tahap saat perkenaan (point of contact), dan tahap gerak lanjutan tahap (follow through) (Brown, 2007:35-35).

Jadi, backhand groundstrokes adalah teknik pukulan dasar dalam permainan bola 
tenis yang dilakukan setelah bola memantul di lapangan dan dilakukan dengan tangan kanan tetapi dari sebelah kiri badan dengan tahapan backswing, point of contact, dan followthrough.

\section{METODE PENELITIAN}

Metode penelitian yang digunakan dalam penelitian ini adalah survei dengan teknik tes, jenis penelitian menggunakan deskriptif kuantitatif yaitu mengenai tingkat kemampuan forehand groundstroke dan backhand groundstroke.

Subjek dalam penelitian ini adalah seluruh siswa sekolah tenis Menoreh Tennis Club, Handayani Tennis Club dan Bantul Tennis Campberjumlah 32 siswa dengan rincian 20 siswa laki-laki dan 12 siswa perempuan.

\section{Pengumpulan Data}

Teknik pengumpulan data dalam penelitian ini menggunakan metode survei dan teknik pengumpulan datanya menggunakan Dyer Tennis Test. Tes dilakukan oleh semua siswa dengan 3 kali kesempatan, setiap kesempatan tes dilakukan selama 30 detik.

Area tes yang diperlukan yaitu dinding yang bermukaan rata, sasaran pada tembok berbentuk persegi panjang dengan ukuran lebar 4,5 meter, tinggi 3 meter, dengan ruangan yang lebar. Pada permukaan tembok dibuat garis net yag sejajar dengan lantai dengan tebal $7,62 \mathrm{~cm}$, garis tepi bawah
Instrumen yang digunakan untuk mengukur tingkat kemampuan forehand groundstrokes dan backhand groundstrokes siswa sekolah tenis Menoreh Tennis Club, Handayani Tennis Club dan Bantul Tennis Campadalah Dyer Tennis Test.

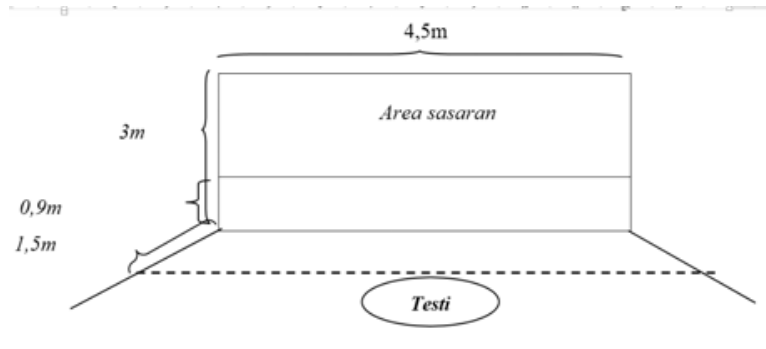

Gambar 1. Dyer Tennis Test ( Ihsan, 2014:29)

Tes Dyer yang asli (sebelum direvisi) validitasnya antara 0,8 sampai 0,90 dengan cara mengkorelasikan skor tes dengan judges ratings. Koefisien reliabilitas tes Dyer yang asli adalah 0,90 (Ngatman, 2001:33).

berjarak $90 \mathrm{~cm}$ dari lantai. Sedangkan untuk jarak testi melakukan tes adalah 1,5 m dari dinding.

Pengambilan data dimulai dengan mengukur kemampuan pukulan forehand groundstroke terlebih dahulu. Semua siswa melakukan forehand groundstroke pada kesempatan pertama, setelah semua melakukan pada kesempatan pertama maka dilanjutkan kesempatan kedua sehingga semua siswa melakukan, dan kemudian kesempatan ketiga. Selanjutnya siswa melakukan backhand groundstroke dengan ketentuan yang sama. 
Teknik analisis data yang digunakan dalam penelitian ini adalah analisis deskriptif dengan persentase. Data yang terkumpul dari masing-masing butir tes yang pertama forehand groundstroke yaitu skor diperoleh dari jumlah ulangan tiga kali kesempatan, masing-masing kesempatan 30 detik melakukan forehand groundstroke. Butir tes yang kedua backhand groundstroke yaitu skor diperoleh dari jumlah ulangan tiga kali kesempatan, masing-masing kesempatan 30 detik melakukan backhand groundstroke. Sedangkan untuk forehand groundstroke dan backhand groundstroke diperoleh dari penjumlahan tiga kali kesempatan forehand groundstroke dan backhand groundstroke yaitu penjumlahan butir tes pertama dan kedua. Sebelumnya akan dikategorikan menjadi 5 kategori berdasarkan nilai mean dan standar deviasi, analisis data tentang tingkat kemampuan forehandgroundstroke dan backhand groundstroke siswa sekolah tenis Menoreh Tennis Club, Handayani Tennis Club dan Bantul Tennis Campyang dituangkan dalam skala pengkategorian berdasarkan tingkat kemampuan siswa dengan menggunakan skala pengkategorian dari Suudijono (2009: 453). Adapun skala pengkategorian adalah sebagai berikut:

Tabel 1. Skala Pengkategorian

\begin{tabular}{ll}
\hline Rentangan Norma & Kategori \\
\hline$<$ Mean $-1,5$ SD & Rendah \\
Mean $-1,5$ SD s.d Mean $-0,5$ SD & Kurang \\
Mean $-0,5$ SD s.d Mean + 0,5 SD & Sedang \\
Mean $+0,5$ SD s.d Mean + 1,5 SD & Baik \\
Mean $+1,5$ SD $<$ & Baik Sekali \\
\hline
\end{tabular}

Keterangan:

Mean = Rerata Kelompok

SD $=$ Standart Deviasi

Statistik deskriptif digunakan dengan tujuan untuk menganalisis data dengan cara mendeskripsikan atau menggambarkan data yang telah terkumpul sebagaimana kemudian diubah dalam bentuk presentase dengan rumus:

$$
\mathrm{P}=\frac{F}{N} \times 100 \%
$$

Keterangan :

$\mathrm{P}=$ hasil presentase

$\mathrm{F}=$ frekuensi

$\mathrm{N}=$ jumlah sampel

\section{HASIL PENELITIAN DAN PEMBAHASAN}

Adapun data hasil penelitian Tingkat Kemampuan Forehand Groundstroke Siswa Sekolah Tenis Menoreh Tennis Club, Handayani Tennis Club dan Bantul Tennis Camp disajikan pada tabel berikut:

\section{Tingkat Kemampuan Forehand Groundstroke}

Tabel 2. Distribusi Frekuensi Kemampuan Forehand Groundstroke 


\begin{tabular}{lllll}
\hline No & Norma & Kategori & Frekuensi & Persentase \\
\hline $\mathbf{1}$ & $<43,21$ & Rendah & 2 & $6,25 \%$ \\
$\mathbf{2}$ & 43,21 s.d 55,94 & Kurang & 8 & $25,00 \%$ \\
$\mathbf{3}$ & 55,95 s.d 68,68 & Sedang & 15 & $46,87 \%$ \\
$\mathbf{4}$ & 68,69 s.d 81,41 & Baik & 5 & $15,63 \%$ \\
$\mathbf{5}$ & $<81,41$ & Baik Sekali & 2 & $6,25 \%$ \\
& Jumlah & & 32 & 100 \\
\hline
\end{tabular}

Berdasarkan tabel di atas, secara rinci sebanyak 2 siswa (6,25\%) mempunyai kemampuan forehand groundstroke rendah, 8 siswa (25\%) berkategori kurang, 15 siswa (46,87\%) berkategori sedang, 5 siswa $(15,63 \%)$ berkategori baik dan 2 siswa (6,25\%) berkategoribaik sekali. Analisis tersebut dapat disajikan dalam bentuk grafik sebagai berikut:

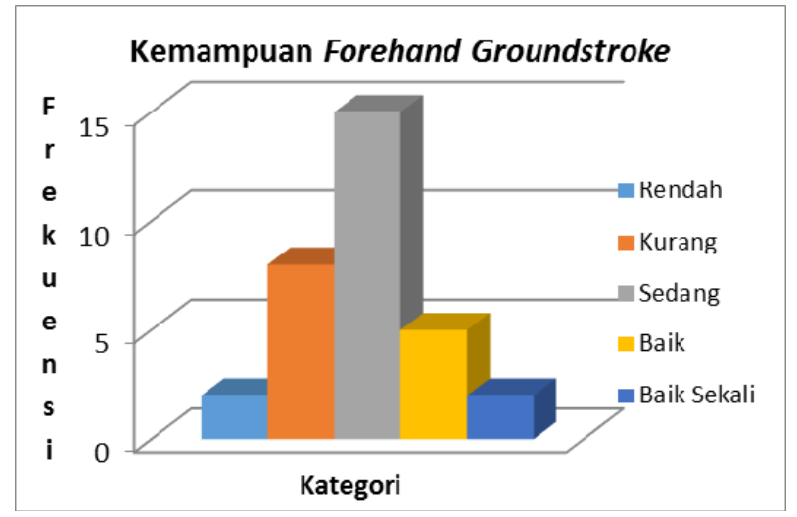

Gambar 1. Histogram Kemampuan Forehand Groundstroke

\section{Tingkat Kemampuan Backhand Groundstroke}

Adapun data hasil penelitian Tingkat Kemampuan Backhand Groundstroke Siswa Sekolah Tenis Menoreh Tennis Club, Handayani Tennis Club dan Bantul Tennis Camp disajikan pada tabel berikut:

Tabel 3. Distribusi Frekuensi Kemampuan Backhand Groundstroke

\begin{tabular}{lllll}
\hline No & Norma & Kategori & Frekuensi & Persentase \\
\hline $\mathbf{1}$ & $<29,02$ & Rendah & 2 & 6,25 \\
$\mathbf{2}$ & 29,02 s.d 45,98 & Kurang & 8 & 25 \\
$\mathbf{3}$ & 45,99 s.d 62,93 & Sedang & 12 & 37,5 \\
$\mathbf{4}$ & 62,94 s.d 79,9 & Baik & 8 & 25 \\
$\mathbf{5}$ & $>799,9$ & Baik Sekali & 2 & 6,25 \\
& Jumlah & & 32 & 100 \\
\hline
\end{tabular}

Berdasarkan tabel distribusi frekuensi kemampuan backhand groundstroke siswa sekolah tenis Menoreh Tennis Club, Handayani Tennis Club dan Bantul Tennis Camp, secara rinci sebanyak 2 siswa (6,25\%) berkategori rendah, 8 siswa (25\%) berkategori kurang, 12 siswa $(37,5 \%)$ berkategori sedang, 8 siswa (25\%) berkategori baik dan 2 siswa $(6,25 \%)$ berkategori baik sekali. Analisis tersebut dapat disajikan dalam bentuk grafik sebagai berikut:

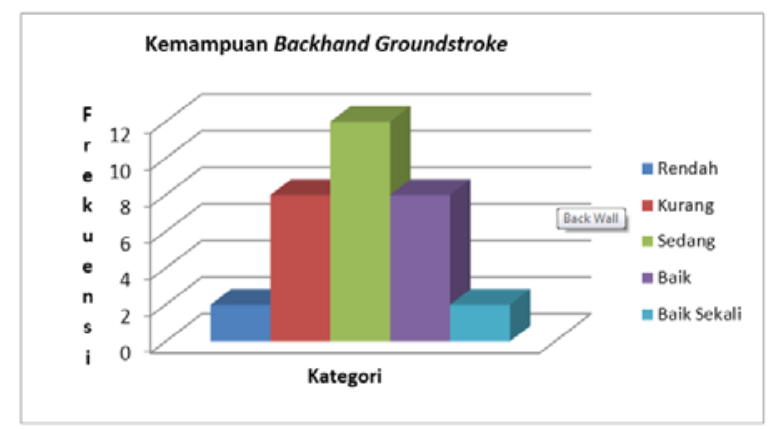

Gambar 2. Histogram Backhand Groundstroke

Kemampuan

\section{Tingkat Kemampuan Forehand Groundstroke dan Backhand Groundstroke}

Tabel 3. Distribusi Frekuensi Kemampuan Forehand Groundstroke dan Backhand Groundstroke 


\begin{tabular}{cccccc}
\hline No & \multicolumn{2}{c}{ Norma } & Kategori & Frekuensi & Persentase \\
\hline $\mathbf{1}$ & $<74,12$ & Rendah & 2 & 6,25 \\
$\mathbf{2}$ & 74,12 & s.d 102,55 & Kurang & 9 & 28,13 \\
$\mathbf{3}$ & 102,56 s.d 130,9 & Sedang & 10 & 31,25 \\
$\mathbf{4}$ & 131 & s.d 159,44 & Baik & 9 & 28,13 \\
$\mathbf{5}$ & $159,44<$ & Baik Sekali & 2 & 6,25 \\
& & & & 32 & 100,01 \\
\hline
\end{tabular}

Berdasarkan tabel distribusi frekuensi kemampuan forehand groundstroke dan backhand groundstroke siswa sekolah tenis Menoreh Tennis Club, Handayani Tennis Club dan Bantul Tennis Camp di atas, secara rinci sebanyak 2 siswa (6,25\%) mempunyai kemampuan forehand groundstroke dan backhand groundstroke rendah, 9 siswa (28,13\%) mempunyai kemampuan forehand groundstroke dan backhand groundstroke kurang, 10 siswa $(31,25 \%)$ mempunyai kemampuan forehand groundstroke dan backhand groundstroke sedang, 9 siswa (28,13\%) mempunyai kemampuan forehand groundstroke dan backhand groundstroke baik dan 2 siswa (6,25\%) mempunyai kemampuan forehand groundstroke dan backhand groundstroke baik sekali. Analisis tersebut dapat disajikan dalam bentuk grafik sebagai berikut:

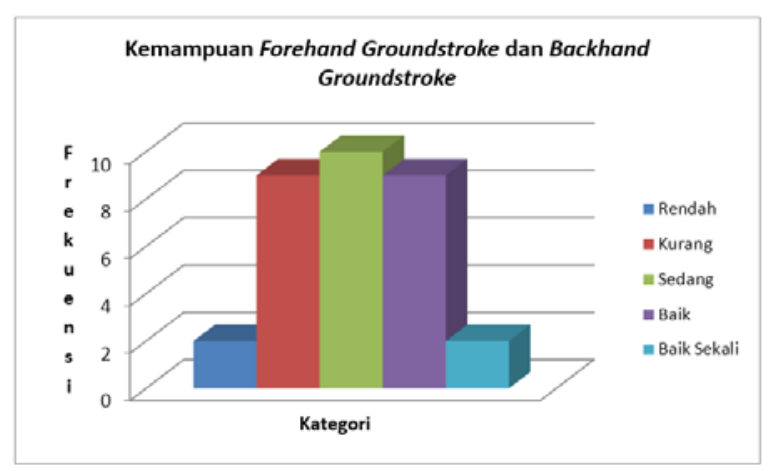

Gambar 3. Histogram Kemampuan Forehand Groundstroke dan Backhand Groundstroke

\section{PEMBAHASAN}

Kemampuan forehand groundstroke dan backhand groundstroke merupakan kemampuan dasar yang harus dimiliki untuk dapat bermain tenis lapangan dengan baik. Kemampuan forehand groundstroke dan backhand groundstrokes perlu dikuasai oleh pemain tenis sejak dini, karena teknik forehand groundstroke dan backhand groundstroke adalah pukulan yang paling dominan dipergunakan pada saat bermain atau bertanding dalam tenis lapangan dan sangat diperlukan pada saat rally-rally panjang pada saat pemain berada di garis belakang(baseline).

Mengajarkan teknik dasar bermain tenis merupakan faktor yang penting dalam permainan tenis lapangan. Penguasaan teknik yang baik akan sangat menunjangefisiensi pelaksanaan gerak, penerapan taktik dan mental bertanding. Oleh sebab itu teknik dasar tenis lapangan harus betul-betul dikuasai agar dapat membantu meningkatkan prestasi tenis bagi petenis usia dini

Siswa sekolah tenis Menoreh Tennis Club, Handayani Tennis Club dan Bantul Tennis Campmemiliki kemampuan forehand groundstroke dan backhand grounstroke “sedang”. Hal ini disebabkan oleh: sebagian anggota sekolah tenis tersebut masih berada pada umur di bawah 12 tahun, sehingga kekuatan otot masih belum optimal dan masih 
dalam masa pertumbuhan dan perkembangan. Pelaksanaan proses latihan forehand groundstrokes dan backhand grounstrokes bagi para tenis belum dilakukan secara teratur, terarah dan berkesinambungan sesuai dengan prinsip-prinsip latihan. Hal ini disebabkan para petenis tersebit masih dalam masa pertumbuhan dan perkembangan sehingga intensitas latihan tidak dapat dipaksakan.

Di samping itu, penggunaan metode drill pada saat memberikan latihanforehand groundstroke dan backhand groundstroke kurang variatif dan kurang menyenangkan bagi anak latih. Atas dasar permasalahan tersebut maka dibutuhkan kemampuan untuk mengemas matode melatih forehand groundstrokes dan backhand grounstrokes yang lebih variatif dan menyenangkan sesuai dengan karakteristik dari siswa.

\section{KESIMPULAN}

Berdasarkan hasil penelitian dapat diketahui bahwa tingkat kemampuan forehand groundstroke siswa sekolah tenis Menoreh Tennis Club, Handayani Tennis Club dan Bantul Tennis Camp berkategori sedang, secara rinci sebanyak 2 siswa $(6,25 \%)$ berkategori baik sekali, 5 siswa $(15,63 \%)$ berkategori baik, 15 siswa (46,87\%) berkategori sedang, 8 siswa (25\%) berkategori kurang dan 2 siswa $(6,25 \%)$ rendah. Tingkat kemampuan backhand groundstroke siswa sekolah tenis Menoreh Tennis Club, Handayani Tennis Club dan
Bantul Tennis Camp dapat diketahui dengan kategori "sedang" dengan rincian sebanyak 2 siswa $(6,25 \%)$ berkategori baik sekali, 8 siswa (25\%) berkategori baik, 12 siswa $(37,5 \%)$ berkategori sedang, 8 siswa $(25 \%)$ berkategori kurang dan 2 siswa (6,25\%) berkategori rendah.

Sedangkan untuk kemampuan Forehand Groundstroke dan Backhand Groundstroke siswa sekolah tenis Menoreh Tennis Club, Handayani Tennis Club dan Bantul Tennis Camp dapat diketahui dalam berkategori sedang. Dengan rincian sebanyak 2 siswa $(6,25 \%)$ berkategori baik sekali, 9 siswa $(28,13 \%)$ berkategori baik, 10 siswa $(31,25 \%)$ berkategori sedang, 9 siswa $(28,13 \%)$ kurang dan 2 siswa $(6,25 \%)$ berkategori rendah.

\section{DAFTAR PUSTAKA}

Abdoelah, Arma dkk. 1981. Olahraga untuk perguruan tinggi. Yogyakarta: PT: Sastra Hudaya.

Arikunto, Suharsimi. 2002. Metodologi Penelitian. Jakarta: PT.Rineka Cipta.

Brown, Jim. 2007. Tenis: Tingkat pemula, alih bahasa dari Tennis: Steps to success. Jakarta: Raja Gravindo Persada.

Hohm, Jindrich and Klavora, Peter, 1987. Tennis Techique and Tactics, Play to Win The Czech Way. Canada: Sport Book Publisher.

Ihsan, Willy. 2014. Tingkat kemampuan forehand groundstrokes dan backhand groundstrokes tenis lapangan siswa 
sekolah tenis selabora FIK UNY. Skripsi: UNY.

Jones, C.M., Angela Buxton. 2006. Belajar tenis untuk pemula. Bandung: Pionir Jaya.

Schuyler, Steve. 1993. Winning Tennis, complete guide for coaches and advanced players. Englexood clifft, N.J: Prentice hall.

Sudijono, Anas. 2009. Pengantar Statistik Pendidikan. Jakarta : PT.Raja Grafindo Persada.

Thahara, Toriq. 2013. Tingkat keterampilan pukulan forehand groundstroke drive dan pukulan backhand groundstroke drive siswa yang mengikuti ekstrakurikuler tenis lapangan di smp negeri 1 Kaliangkrik Kabupaten Magelang tahun ajaran 2012/ 2013.Skripsi: UNY 